\title{
A novel flow cytometric method for enhancing acute promyelocytic leukemia screening by multidimensional dot-plots
}

\author{
Bettina Kárai ${ }^{1}$ (I) Mira Habók ${ }^{1}$ • Gyula Reményi ${ }^{2}$ - László Rejtő ${ }^{3}$ - Anikó Ujfalusi ${ }^{1}$ - János Kappelmayer ${ }^{1}$. \\ Zsuzsanna Hevessy ${ }^{1}$
}

Received: 10 July 2018 / Accepted: 19 February 2019 / Published online: 4 March 2019

(C) The Author(s) 2019

\begin{abstract}
Acute promyelocytic leukemia (APL) is generally characterized by $\mathrm{t}(15 ; 17)(\mathrm{q} 24 ; \mathrm{q} 21)$. In some cases, the classic translocation cannot be identified by conventional methods, since the PML-RARA fusion protein results from complex, variant, or cryptic translocation. The diagnostic algorithm of APL starts with screening methods, such as flow cytometry (FC), followed by fluorescence in situ hybridization or polymerase chain reaction to confirm the diagnosis. Our aim was to develop a novel protocol for analyzing APL samples based on multidimensional dot-plots that can provide comprehensive information about several markers at the same time. The protocol included four optimized multidimensional dot-plots, which were tested by retrospective reanalysis of FC results in APL $(n=8)$ and non-APL $(n=12)$ acute myeloid leukemia (AML) cases. After predicting the potential position of hypergranular- and microgranular-type aberrant promyelocytes, the percentages of blast populations were examined within the gates in all AML cases. The percentage of blasts in each predefined gate was well above the cut-off value (95\%) in APL cases in all tubes. In non-APL AML cases, the percentage of blasts in the same gates never reached the cut-off value in all investigated tubes, and even when it did in a single tube, the pattern was markedly different from that observed in APL cases. In conclusion, multidimensional dot-plots can be used for screening APL even in cryptic APL cases, although reproducibility across several laboratories would require standardization of antibodies and fluorochromes. This easy-to-use and quick method can support the diagnosis of APL and the prompt initiation of the appropriate treatment.
\end{abstract}

Keywords Acute promyelocytic leukemia $\cdot$ Flow cytometry $\cdot$ Multidimensional dot-plot $\cdot$ Cryptic translocation

\section{Introduction}

Genetic alterations determine the biological behavior of acute myeloid leukemia (AML); therefore, these are the most effective independent prognostic factors and serve as the basis of

Electronic supplementary material The online version of this article (https://doi.org/10.1007/s00277-019-03642-w) contains supplementary material, which is available to authorized users.

Bettina Kárai

karai.bettina@med.unideb.hu

1 Department of Laboratory Medicine, University of Debrecen, Nagyerdei krt. 98, Debrecen H-4032, Hungary

2 Department of Internal Medicine, Faculty of Medicine, University of Debrecen, Debrecen, Hungary

3 Department of Hematology, Jósa András County Hospital, Nyíregyháza, Hungary classifications and guidelines [1,2]. The recommendation of the World Health Organization (WHO) classifies AML according to recurrent genetic abnormalities, which are associated with specific clinicopathological features. Acute promyelocytic leukemia (APL) is mostly caused by the PML-RARA fusion protein [3]. The promyelocytic leukemia $(P M L)$ gene is located on chromosome 15, while retinoic acid receptor alpha $(R A R A)$ on chromosome 17 [1]. The balanced reciprocal classic $\mathrm{t}(15 ; 17)(\mathrm{q} 24 ; \mathrm{q} 21)$ translocation is detected in $90-92 \%$ of APL patients $[4,5]$. In the remaining cases, complex translocations involving chromosomes 15 and 17 or a submicroscopic insertion result in the rise of $P M L$ RARA transcript [1]. On the basis of the morphological appearances of aberrant promyelocytes, APL can be classified as hypergranular or microgranular [1]. The release of procoagulant mediators from the leukemic cells is likely the most important mechanism, which is responsible for APLassociated coagulopathy. Disseminated intravascular coagulopathy (DIC) and systemic fibrinolysis, which usually occurs 
at the time of diagnosis, are the major causes of early death [6-8]. The immediate administration of retinoid differentiating agents, such as all-trans retinoic acid (ATRA) and arsenic trioxide, reduce the hemorrhagic complications of APL; moreover, chemotherapy completed with ATRA improves overall survival [9-13]. Therefore, rapid diagnosis and prompt treatment are indispensable. The diagnostic algorithm of APL starts with morphology and immunophenotype examinations [2]. Classic APL is characterized by a distinct morphology; yet, the microgranular type can mimic acute monoblastic leukemia, where the clinical history also resembles APL regarding coagulopathy $[1,14]$. The common immunophenotypic alterations in APL, such as CD117, CD64, cytoplasmic MPO, CD33 bright expression, and loss or only weak intensity of CD34 and HLA-DR expression, have been known for decades; however, these are not specific for APL [1]. The morphology and immunophenotype examination serve as screening, and the detection of $\mathrm{t}(15 ; 17)$ confirms the diagnosis. Fluorescence in situ hybridization (FISH) is the most commonly used method for the identification of $t(15 ; 17)$. In rare cases of APL that do not harbor the classic cytogenetically visible translocation but still possess the PML-RARA rearrangement, the polymerase chain reaction (PCR) is crucial for detecting the fusion gene $[4,5,15,16]$.

Due to the use of multiple lasers and an increasing number of fluorochromes, more information can be obtained from cells by flow cytometric examinations, which lead to the increasing significance of this method. Our aim was to exploit the opportunities afforded by recent improvements in analysis software, which can handle such large amounts of data. We wanted to assess a new analysis protocol based on multidimensional radar dot-plot that was designed to expand the effectiveness of flow cytometric examination in the screening of APL. To test this protocol, we compared the results of an APL AML group to those of a non-APL AML group with the help of predefined gates around the blasts characterized by the most common immunophenotype in APL.

\section{Material and methods}

\section{Study design}

We examined retrospectively the data of patients referred to the Department of Laboratory Medicine (University of Debrecen, Hungary) between May 2014 and December 2017 for detailed examination. On the basis of clinical history, morphological, flow cytometric, cytogenetic, and molecular examinations, two groups were formed: an APL group with eight patients and a non-APL group with 12 patients. Six patients with APL had classic $\mathrm{t}(15 ; 17)$ translocation. One patient had complex karyotype affecting one additional chromosome beside chromosomes 15 and 17. Furthermore, one patient had cryptic APL, where the fusion gene could be detected only by PCR. The non-APL group was designed to include only those AML cases, which were characterized by myeloblasts that mimic the immunophenotype of APL. Their myeloblasts were $\mathrm{CD} 117$ positive, CD33 bright, and CD34 negative - this is the immunophenotype pattern most characteristic of APL. All patients in the non-APL group had normal karyotype and mutated NPM1 because this genetic feature is associated with CD34 negative myeloblasts [17-20]. The clinical and laboratory parameters of patients are summarized in Table 1. Bone marrow aspiration samples were examined by May-Grünwald-Giemsa staining and $\times 1000$ magnification.

\section{Flow cytometry}

The bone marrow samples were examined routinely by eight color-labeling procedure with a four-tube AML panel for diagnostic purposes. The antibodies we examined are shown in Table 2.

CD14, CD11b, HLA-DR, CD45, CD64, CD13, CD15, CD34, CD71, CD117, CD300e, CD4, and CD10 markers were purchased from the Becton Dickinson Biosciences (San Jose, CA, USA); CD33, CD16,CD2, CD117, and CD13 markers were purchased from the Beckman Coulter (Brea, CA, USA); CD45 marker was purchased from Invitrogen (Thermo Scientific Inc., Waltham, MA, USA); HLA-DR marker was purchased from Biolegend (San Diego, CA, USA), and cytoplasmic MPO (cyMPO) was purchased from Dako (Santa Clara, CA, USA). Generation and labeling of mouse monoclonal antibodies against FXIII-A subunit was carried out utilizing a FITC labeling kit (Sigma, St. Louis, MO) [21]. The labeling procedure was

Table 1 Clinical and laboratory parameters of patients

\begin{tabular}{lll}
\hline & APL $(n=8)$ & Non-APL $(n=12)$ \\
\hline Age (year) & $53(32-74)$ & $64(50-80)$ \\
Gender $($ female/male $)$ & $4 / 4$ & $9 / 3$ \\
WBC $\left(\times 10^{9} \mathrm{~L}\right)$ & $17.01(0.46-56.1)$ & $88.12(8.3-303)$ \\
Hypergranular type & $9.56(0.46-22.45)$ & \\
Microgranular type & $35.64(15.2-56.1)$ & \\
HB $(\mathrm{g} / \mathrm{L})$ & $96(77-115)$ & $81(49-138)$ \\
PLT $\left(\times 10^{9} \mathrm{~L}\right)$ & $38(8-85)$ & $118(28-274)$ \\
LDH $(\mathrm{U} / \mathrm{L})$ & $806(173-2266)$ & $1345(214-8194)$ \\
Blast\% in bone marrow & $63.5(26.6-87.5)$ & $54.8(20.7-82.9)$ \\
DIC & $8 / 8$ & $0 / 12$ \\
FLT3 ITD $(+/-/ n)$ & $3 / 3 / 2$ & $4 / 8 / 0$ \\
FLT3 TKD $(+/-/ n)$ & $0 / 6 / 2$ & $0 / 12 / 0$ \\
NPMI $(+/-/ n)$ & $0 / 6 / 2$ & $12 / 0 / 0$ \\
\hline
\end{tabular}

Abbreviations: WBC: white blood cell count, $H B$ : hemoglobin, PLT: platelet count, FLT3 ITD: FLT3 internal tandem duplication, FLT3 TKD: FLT3 tyrosine kinase domain, NMP1: nucleophosmin, $n$ : not done 
performed as previously described [22]. One hundred thousand events were acquired with the help of FACS Canto II flow cytometer (Becton Dickinson Biosciences, San Jose, CA, USA). To make the results comparable, the flow cytometer was calibrated daily, using cytometer setup and tracking fluorescent microbeads (Cat No. 641319, Becton Dickinson Biosciences, San Jose, CA, USA) and Autocomp software as recommended by the manufacturer. Data was analyzed by Kaluza Software version 1.2 (Beckman Coulter, Brea, CA, USA).

Bivariate dot-plots were used to analyze the detailed immunophenotype of leukemic cells. The threshold of positivity was set to $>10 \%$ positive leukemic cells for MPO and to $>20 \%$ for all other antigens, in accordance with the threshold conventions apparent in the literature $[1,23]$.

To create an analysis protocol for APL, one multidimensional radar dot-plot was optimized for each of the four tubes. The software allows selecting the number and the position of parameters in the radar dot-plot, which influence the appearance of blast population in the dot-plot. The optimization procedure was the following: First, the files of three AML patients characterized by different morphology (M2, M4, APL) were merged, and then the three blast populations were gated by CD45/SSC bivariate dot-plot. Subsequently the three different blast populations were presented in one radar dot-plot, and those parameters and locations were selected whereby the three populations differed from each other the most (for tube 1, these were SSC, CD4, CD64, CD11b, CD13, HLA-DR, CD14, CD300e, CD45; for tube 2, CD15, CD123, SSC, CD34, CD13, HLA-DR, CD45, for tube 3, CD34, CD117, CD56, CD45, CD33, SSC, and for tube 4, these were cyFXIII-A, cyMPO, HLA-DR, SSC, CD117, CD45). Finally, we merged all hypergranular APL cases to designate gates for the expected positions of $95 \%$ (cut-off value) of hypergranular APL blast populations. Because the location of microgranular-type APL differed from hypergranular cases, a microgranular gate could be defined on the basis of the two microgranular cases.

\section{Chromosome analysis, FISH, and molecular analysis}

G-banding was performed according to standard procedures on all samples of APL and non-APL patients. Karyotypes were described according to the International System of Human Cytogenetic Nomenclature. Fluorescence in situ hybridization was carried out on cell suspension samples used for chromosome analysis according to the manufacturer's instructions, using PML/RARA DC, DF translocation probes (Metasystems, Altlussheim, Germany).

\section{Statistical analysis}

Considering the low number of samples median, 25th and 75th percentile values were used. Statistical analysis and the creation of figures were carried out using GraphPad Prism 6.0 (GraphPad Software, San Diego, CA, USA) statistical program.

\section{Results}

\section{Morphological characterization of patients with APL and non-APL AML}

In the APL group, two patients displayed microgranular- and six patients with hypergranular-type APL. The myeloblasts of three patients in the non-APL group were characterized by agranular cytoplasm, showing distinct blebs, or pseudopod formation. Two patients had "cup-like" blasts. According to the French-American-British (FAB) classification, five of the remaining cases exhibited M4 morphology, one M0/M1, and one M2. The representative morphologic appearance of blasts in the APL is shown on Online Resource 1, respectively.

\section{Immunophenotypic characterization of patients with APL and non-APL AML}

In accordance with the findings of the morphological examination, the aberrant promyelocytes had high side scatter (SSC) in six cases (hypergranular type) and medium intensity SSC in two cases (microgranular type). The immunophenotypes of promyelocytes are summarized in Table 3. Aberrant promyelocytes were characterized by a frequently detected pattern in APL: in hypergranular cases, promyelocytes expressed only CD117 of blast markers, while they expressed all myeloid markers (CD33, CD13, cyMPO) with high intensity. Blasts were CD15 negative in all cases. Regarding leukemia-associated immunophenotype (LAIP) and prognostic markers, CD56 and CD2 were positive in one case, while cytoplasmic FXIII-A was positive in all cases.

In the non-APL group, myeloblasts (MB) were characterized by monocytic immunophenotype in five cases, in accordance with the morphological findings. CD123 and cyFXIIIA were positive in $75 \%$ of the cases (Table 3 ).

\section{Multidimensional map of APL}

Regardless of the mechanism that lead to the formation of the PML-RARA fusion protein, more than $95 \%$ of blasts detected in the hypergranular gate were observed in all hypergranulartype APL cases (Fig. 1a). As for the microgranular-type APL cases, the position of the blast population differed from what we found in the hypergranular-type APL cases; therefore, dedicated gates were set up to predict the position of microgranular blasts (Fig. 2). The microgranular blasts were located within their respective gate (the median percentages of blasts within the microgranular gate were $96.1 \%$ for tube $1,96.5 \%$ for tube 2 , 
Table 2 Antibody combinations used in flow cytometric examination for the diagnosis of AML

\begin{tabular}{lllllllll}
\hline & FITC & PE & PerCP-Cy5.5/PC5.5 & PC7 & APC & APC-AF750 & PB & PO \\
\hline 1. & CD14 & CD11b & HLA-DR & CD13 & CD300e & CD64 & CD4 & CD45 \\
2. & CD15 & CD123 & CD34 & CD13 & CD10 & CD16 & HLA-DR & CD45 \\
3. & CD71 & CD117 & CD33 & CD56 & CD34 & CD38 & CD7 & CD45 \\
4. & cyFXIII-A & cyMPO & CD33 & CD2 & CD34 & CD117 & HLA-DR & CD45 \\
\hline
\end{tabular}

Abbreviations: $c y F X I I I-A$ : cytoplasmic A subunit of blood coagulation factor XIII; $c y M P O$ : cytoplasmic myeloperoxidase, FITC: fluorescein isothiocyanate, $P E$ : phycoerythrin, $P e r C P-C y 5.5$ : peridinin chlorophyll protein 5.5, PC5.5: phycoerythrin cyanin 5.5, PC7: phycoerythrin cyanin 7, APC: allophycocyanin, $A P C-A F 750$ : conjugation allophycocyanin-alexa fluor $750, P B$ : pacific blue, $P O$ : pacific orange
$98 \%$ for tube 3 , and $97 \%$ for tube 4$)$. The percentage of blasts was well above not only the cut-off value $(95 \%)$ in both hyperand microgranular-type APL AML cases in all the four tubes (Fig. 1) but also the patterns of blasts within the gates corresponding to their types that were similar in all the cases.

In most cases of the non-APL AML patient group, blasts within the gate typically did not reach the cut-off value. It was only in tube 3-which contained the criteria markers (CD117, CD34) used for creating the non-APL AML group - that the percentage of blasts in the hypergranular gate surpassed the cut-off value (Fig. 1); but even here, the pattern of the blasts within the gate differed from what we detected in the APL AML group: the blasts were not dispersed evenly throughout the gate but concentrated in its upper segment (Fig. 2, tube 3). Similarly to the hypergranular APL gates, there were only one non-APL AML case which reached the cut-off value in the

Table 3 Antigen expression by leukemic cells

\begin{tabular}{|c|c|c|c|}
\hline & \multicolumn{2}{|l|}{ APL } & \multirow{2}{*}{$\begin{array}{l}\text { Non-APL AML } \\
n=12\end{array}$} \\
\hline & $\begin{array}{l}\text { hypergranular } \\
\text { type }(n=6)\end{array}$ & $\begin{array}{l}\text { microgranular } \\
\text { type }(n=2)\end{array}$ & \\
\hline CD117 & $100 \%$ & $100 \%$ & $100 \%$ \\
\hline CD34 & $0 \%$ & $100 \%$ & $0 \%$ \\
\hline HLA-DR & $0 \%$ & $0 \%$ & $58 \%$ \\
\hline CD33 & $100 \%$ & $100 \%$ & $100 \%$ \\
\hline CD13 & $100 \%$ & $100 \%$ & $100 \%$ \\
\hline суMPO & $100 \%$ & $100 \%$ & $83 \%$ \\
\hline CD14 & $0 \%$ & $0 \%$ & $42 \%$ \\
\hline CD11b & $0 \%$ & $0 \%$ & $42 \%$ \\
\hline CD64 & $50 \%$ & $50 \%$ & $42 \%$ \\
\hline $\mathrm{CD} 4$ & $0 \%$ & $0 \%$ & $42 \%$ \\
\hline CD15 & $0 \%$ & $0 \%$ & $42 \%$ \\
\hline CD123 & $0 \%$ & $100 \%$ & $75 \%$ \\
\hline CD56 & $17 \%$ & $0 \%$ & $25 \%$ \\
\hline CD38 & $100 \%$ & $100 \%$ & $100 \%$ \\
\hline CD7 & $0 \%$ & $50 \%$ & $25 \%$ \\
\hline $\mathrm{CD} 2$ & $17 \%$ & $100 \%$ & $0 \%$ \\
\hline cyFXIII-A & $100 \%$ & $100 \%$ & $75 \%$ \\
\hline
\end{tabular}

pre-defined microgranular gate in tube 1, and in some cases, the percentage of $\mathrm{MB}$ in the microgranular-type gate approached the cut-off value. The pattern of MB in the microgranular gate, however, differed from the position of microgranular APL cells. The representative multidimensional dot-plots in the APL and non-APL AML groups are shown in Figs. 2 and 3.

\section{Discussion}

The major finding of our study was that with the help of predefined gates in a multidimensional radar dot-plot, an effective, reproducible, and quick protocol can be created for the screening of APL. Recently, routinely used flow cytometric analyzing software (e.g., Kaluza and Infinicyt) allows integrated data visualization, which improves the interpretation of a large amount of data generated by an increasing number of fluorochromes. The comprehensive dot-plots were used first in the identification of normal cell populations during maturation [24, 25]. When the position of normal cell types was mapped, on the one hand, the detection of alterations from the normal pattern permit the identification of characteristic dysplastic signs referred to as myeloproliferative disorders [24]. On the other hand, several studies have demonstrated that the appearance of aberrant cells on integrated dot-plots was associated with a distinct malignancy, which can be utilized in the detection of minimal residual disease [26-28].

To the best of our knowledge, we were the first to examine APL with multidimensional dot-plots based on a wide range of markers. We used not only the markers the expression of which was frequently altered in APL (CD34, CD117, HLADR, CD15, cyMPO, CD13, CD33, CD64) but also the prognostic markers, such as CD56, CD7, CD2, and cyFXIII-A [22, 29-32]. The expression of CD56 or CD7 marker is associated with poor prognosis [29], while the presence of cyFXIII-A or CD2 with good prognosis [22, 31].

We found that the aberrant promyelocytes can be characterized by unique patterns and positions on radar dot-plots regardless of the mechanism leading to the formation of PML-RARA fusion protein. Therefore, the results of these dot-plots can 


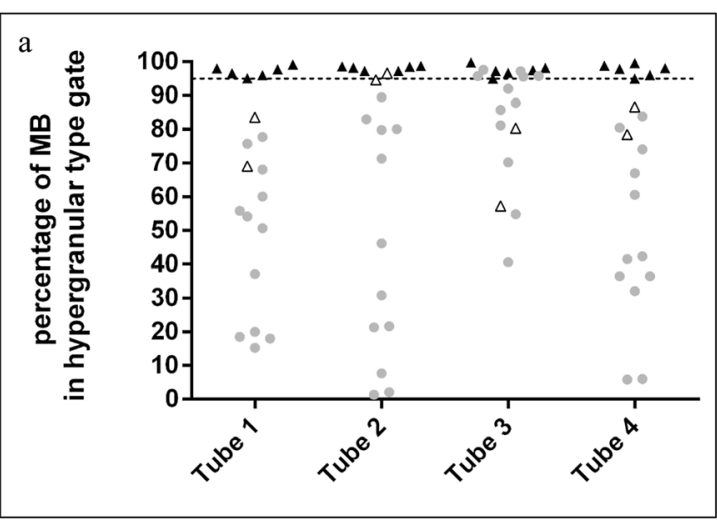

Fig. 1 The percentage of blasts in hypergranular- (a) and microgranulartype gates (b). The black triangles indicate hypergranular APL cases, the white ones the microgranular-type APL cases, while the gray circles

support the diagnosis of APL even in FISH-negative - cryptic - cases and indicate the performance of PCR examination as early as possible to confirm the diagnosis.

In addition, with the help of multidimensional dot-plots, more information can be obtained from blast cells with a single examination; therefore, APL cases can be differentiated from all types of AML, including CD34-negative cases. Earlier several studies confirmed the usefulness of bivariate dot-plots in the screening of APL cases within AML. These were based only on three or four markers, usually CD34, HLA-DR, and a

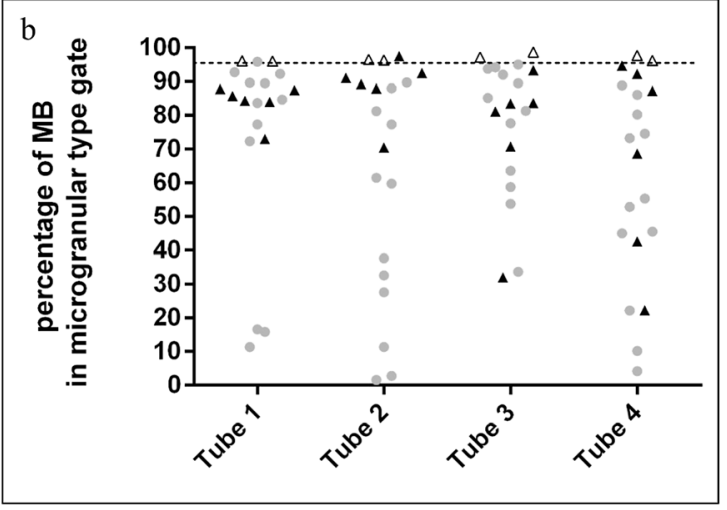

indicate non-APL AML cases. The horizontal line represents the cut-off value $(95 \%)$

marker indicative of maturation, such as CD15 or CD11b [30, 33, 34]. These bivariate dot-plots, however, were characterized by high specificity and sensitivity $(>90 \%)$ only with respect to all types of AML, most of which are CD34-positive cases. Our novel protocol based on multivariate dot-plots, in turn, brings the most value where the applicability of bivariate dot-plots is limited: differentiating between APL and AML with CD34and/or HLA-DR-negative immunophenotype. More and more information has been accumulated over the past decade about this less common type of AML. It is characterized by normal
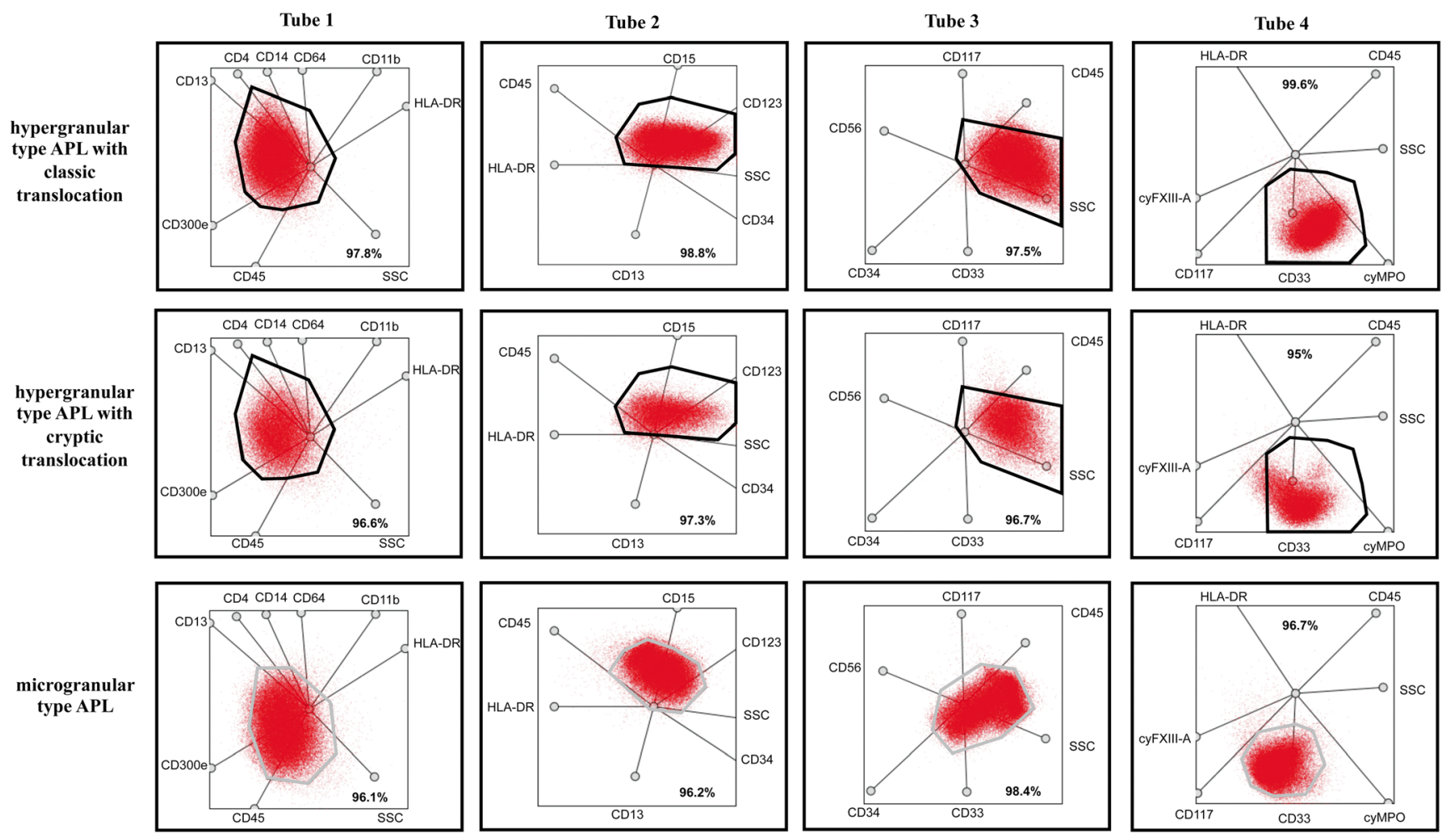

Fig. 2 Representative dot-plots for various APL cases. Representative dot-plots of a hypergranular type APL with classic translocation are in the first line, dot-plots of hypergranular type APL with cryptic translocation are in the second, and microgranular type APL are in the third line.

The bold frame indicates the hypergranular-gate, and gray one indicates the microgranular-gate. Red indicates blasts. The bold numbers indicate the percentage of blasts in gates predicted for one of the pre-defined type of APL-gate 

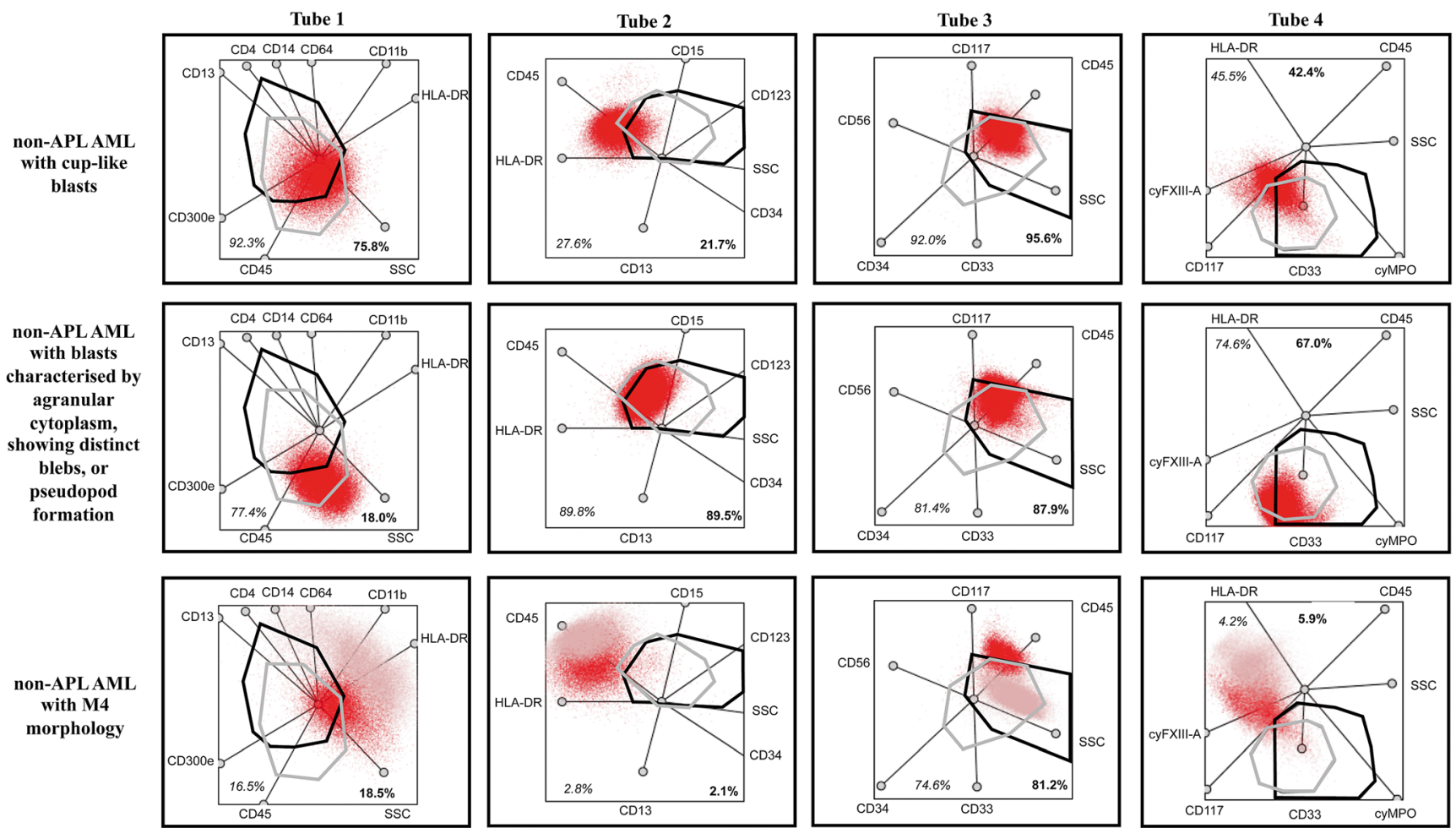

Fig. 3 Representative dot-plots for various non-APL AML cases. Dotplots of a non-APL AML with cup-like blasts are in first line, dot-plots of non-APL AML with blasts characterized by agranular cytoplasm, showing distinct blebs, or pseudopod formation are in the second and dot-plots of a non-APL with M4 morphology are in third line. The bold frame indicates the hypergranular-gate, and gray frame predicted microgranular-APL. Red indicates blasts; pink represents monocytes. The bold numbers indicate the percentage of blasts in gates predicted for hypergranular-type APL and represent the percentage of blasts in gates predicted for microgranular-type APL karyotype, NPM1 mutation, and morphologically by "cuplike" blasts and M2 or M4 morphology as defined by FAB [17-20, 35, 36]. Despite these common denominators, morphology suggests that this is not a homogeneous subtype of AML, and yet, another advantage of our protocol is that it can detect various patterns among CD34-negative non-APL cases. Thus radar dot-plots enable the more precise identification of similarly behaving AML cases.

It must be acknowledged that there are some limitations to this study. For three reasons, we were able to examine only a relatively small number of APL cases. First, APL is relatively uncommon in Hungary; secondly, radar dot-plots can be used to compare cases where the same antibodies and fluorochromes have been used; and thirdly, the eight-color staining method has been used in Hungary only since 2014. Therefore, a control study on a larger population would be necessary in order to validate our results. In addition, we examined only APL cases with $P M L-R A R A$ fusion, but $R A R A$ may have other fusion partners, such as ZBTB16, NUMA1, STAT5B, or NPM1. The variant fusion partner is important because it can influence the prognosis through the response to ATRA. Sainty et al., who examined a large number of cases with APL lacking $\mathrm{t}(15 ; 17)$, found that ZBTB16-RARA cases were associated with CD56 expression, and there were no other immunophenotypic differences from $\mathrm{t}(15 ; 17)$ APL [37], which suggests that our multidimensional screening protocol could be used in those cases as well.

In conclusion, multidimensional (radar) dot-plots can be used for screening APL even in cryptic APL cases. Based on only four multidimensional dot-plots, our protocol examined 6-9 markers per tube at the same time, thus increasing the efficiency and effectiveness of the FC examination. This method is reproducible (within the same laboratory), easyto-use, and quick regardless of the percentage of blasts size and can differentiate squarely between APL and non-APL AML cases even when the FC results based on bivariate dotplots would be uncertain and suggest APL falsely. This differentiation is crucial, because APL requires the prompt administration of special treatment to achieve a favorable prognosis.

Funding Information Open access funding provided by University of Debrecen (DE).

\section{Compliance with ethical standards}

We conducted our studies in compliance with the principles of the Declaration of Helsinki.

Conflict of interest The authors declare that they have no conflicts of interest. 
Open Access This article is distributed under the terms of the Creative Commons Attribution 4.0 International License (http:// creativecommons.org/licenses/by/4.0/), which permits unrestricted use, distribution, and reproduction in any medium, provided you give appropriate credit to the original author(s) and the source, provide a link to the Creative Commons license, and indicate if changes were made.

Publisher's note Springer Nature remains neutral with regard to jurisdictional claims in published maps and institutional affiliations.

\section{References}

1. Arber DA, Orazi A, Hasserjian R, Thiele J, Borowitz MJ, Le Beau MM, Bloomfield CD, Cazzola M, Vardiman JW (2016) The 2016 revision to the World Health Organization classification of myeloid neoplasms and acute leukemia. Blood 127(20):2391-2405. https:// doi.org/10.1182/blood-2016-03-643544

2. Dohner H, Estey E, Grimwade D, Amadori S, Appelbaum FR, Buchner T, Dombret H, Ebert BL, Fenaux P, Larson RA, Levine RL, Lo-Coco F, Naoe T, Niederwieser D, Ossenkoppele GJ, Sanz M, Sierra J, Tallman MS, Tien HF, Wei AH, Lowenberg B, Bloomfield CD (2017) Diagnosis and management of AML in adults: 2017 ELN recommendations from an international expert panel. Blood 129(4):424-447. https://doi.org/10.1182/blood-201608-733196

3. Rowley JD, Golomb HM, Dougherty C (1977) $15 / 17$ translocation, a consistent chromosomal change in acute promyelocytic leukaemia. Lancet 1(8010):549-550

4. Grimwade D, Biondi A, Mozziconacci MJ, Hagemeijer A, Berger R, Neat M, Howe K, Dastugue N, Jansen J, Radford-Weiss I, Lo Coco F, Lessard M, Hernandez JM, Delabesse E, Head D, Liso V, Sainty D, Flandrin G, Solomon E, Birg F, Lafage-Pochitaloff M (2000) Characterization of acute promyelocytic leukemia cases lacking the classic $\mathrm{t}(15 ; 17)$ : results of the European Working Party. Groupe Francais de Cytogenetique Hematologique, Groupe de Francais d'Hematologie Cellulaire, UK Cancer Cytogenetics Group and BIOMED 1 European Community-Concerted Action "Molecular Cytogenetic Diagnosis in Haematological Malignancies". Blood 96(4):1297-1308

5. Kim M, Lim J, Kim Y, Han K, Lee DH, Chung NG, Cho B, Kim HK, Eom KS, Min CK, Min WS (2008) The genetic characterization of acute promyelocytic leukemia with cryptic $t(15 ; 17)$ including a new recurrent additional cytogenetic abnormality i(17)(q10). Leukemia 22(4):881-883. https://doi.org/10.1038/sj.leu.2404989

6. Breen KA, Grimwade D, Hunt BJ (2012) The pathogenesis and management of the coagulopathy of acute promyelocytic leukaemia. Br J Haematol 156(1):24-36. https://doi.org/10.1111/j.13652141.2011.08922.x

7. Rickles FR, Falanga A, Montesinos P, Sanz MA, Brenner B, Barbui $T$ (2007) Bleeding and thrombosis in acute leukemia: what does the future of therapy look like? Thromb Res 120(Suppl 2):S99-S106. https://doi.org/10.1016/S0049-3848(07)70137-8

8. Tallman MS, Kwaan HC (1992) Reassessing the hemostatic disorder associated with acute promyelocytic leukemia. Blood 79(3): 543-553

9. Lo-Coco F, Avvisati G, Vignetti M, Breccia M, Gallo E, Rambaldi A, Paoloni F, Fioritoni G, Ferrara F, Specchia G, Cimino G, Diverio D, Borlenghi E, Martinelli G, Di Raimondo F, Di Bona E, Fazi P, Peta A, Bosi A, Carella AM, Fabbiano F, Pogliani EM, Petti MC, Amadori S, Mandelli F, Italian GCG (2010) Front-line treatment of acute promyelocytic leukemia with AIDA induction followed by risk-adapted consolidation for adults younger than 61 years: results of the AIDA-2000 trial of the GIMEMA Group. Blood 116(17): 3171-3179. https://doi.org/10.1182/blood-2010-03-276196

10. Park JH, Qiao B, Panageas KS, Schymura MJ, Jurcic JG, Rosenblat TL, Altman JK, Douer D, Rowe JM, Tallman MS (2011) Early death rate in acute promyelocytic leukemia remains high despite all-trans retinoic acid. Blood 118(5):1248-1254. https://doi.org/ 10.1182/blood-2011-04-346437

11. Mandelli F, Diverio D, Avvisati G, Luciano A, Barbui T, Bernasconi C, Broccia G, Cerri R, Falda M, Fioritoni G, Leoni F, Liso V, Petti MC, Rodeghiero F, Saglio G, Vegna ML, Visani G, Jehn U, Willemze R, Muus P, Pelicci PG, Biondi A, Lo Coco F (1997) Molecular remission in PML/RAR alpha-positive acute promyelocytic leukemia by combined all-trans retinoic acid and idarubicin (AIDA) therapy. Gruppo Italiano-Malattie Ematologiche Maligne dell'Adulto and Associazione Italiana di Ematologia ed Oncologia Pediatrica Cooperative Groups. Blood 90(3):1014-1021

12. Fenaux P, Chastang C, Chevret S, Sanz M, Dombret H, Archimbaud E, Fey M, Rayon C, Huguet F, Sotto JJ, Gardin C, Makhoul PC, Travade P, Solary E, Fegueux N, Bordessoule D, Miguel JS, Link H, Desablens B, Stamatoullas A, Deconinck E, Maloisel F, Castaigne S, Preudhomme C, Degos L (1999) A randomized comparison of all transretinoic acid (ATRA) followed by chemotherapy and ATRA plus chemotherapy and the role of maintenance therapy in newly diagnosed acute promyelocytic leukemia. The European APL Group. Blood 94(4):1192-1200

13. Sanz MA, Martin G, Rayon C, Esteve J, Gonzalez M, DiazMediavilla J, Bolufer P, Barragan E, Terol MJ, Gonzalez JD, Colomer D, Chillon C, Rivas C, Gomez T, Ribera JM, Bornstein R, Roman J, Calasanz MJ, Arias J, Alvarez C, Ramos F, Deben G (1999) A modified AIDA protocol with anthracycline-based consolidation results in high antileukemic efficacy and reduced toxicity in newly diagnosed PML/RARalpha-positive acute promyelocytic leukemia. PETHEMA Group. Blood 94(9):3015-3021

14. Tobelem G, Jacquillat C, Chastang C, Auclerc MF, Lechevallier T, Weil M, Daniel MT, Flandrin G, Harrousseau JL, Schaison G, Boiron M, Bernard J (1980) Acute monoblastic leukemia: a clinical and biologic study of 74 cases. Blood 55(1):71-76

15. Blanco EM, Curry CV, Lu XY, Sarabia SF, Redell MS, LopezTerrada DH, Roy A (2014) Cytogenetically cryptic and FISHnegative PML/RARA rearrangement in acute promyelocytic leukemia detected only by PCR: an exceedingly rare phenomenon. Cancer Genet 207(1-2):48-49. https://doi.org/10.1016/j.cancergen. 2014.01.001

16. Rashidi A, Fisher SI (2015) FISH-negative, cytogenetically cryptic acute promyelocytic leukemia. Blood Cancer J 5:e320. https://doi. org/10.1038/bcj.2015.47

17. Thiede C, Koch S, Creutzig E, Steudel C, Illmer T, Schaich M, Ehninger G (2006) Prevalence and prognostic impact of NPM1 mutations in 1485 adult patients with acute myeloid leukemia (AML). Blood 107(10):4011-4020. https://doi.org/10.1182/blood2005-08-3167

18. Falini B, Mecucci C, Tiacci E, Alcalay M, Rosati R, Pasqualucci L, La Starza R, Diverio D, Colombo E, Santucci A, Bigerna B, Pacini R, Pucciarini A, Liso A, Vignetti M, Fazi P, Meani N, Pettirossi V, Saglio G, Mandelli F, Lo-Coco F, Pelicci PG, Martelli MF, Party GALW (2005) Cytoplasmic nucleophosmin in acute myelogenous leukemia with a normal karyotype. N Engl J Med 352(3):254-266. https://doi.org/10.1056/NEJMoa041974

19. Mori Y, Yoshimoto G, Kumano T, Miyamoto T, Iino T, Takenaka K, Iwasaki H, Harada N, Kinukawa N, Nagafuji K, Teshima T, Shimoda K, Akashi K, Harada M (2007) Distinctive expression of myelomonocytic markers and down-regulation of CD34 in acute myelogenous leukaemia with FLT3 tandem duplication and nucleophosmin mutation. Eur J Haematol 79(1):17-24. https:// doi.org/10.1111/j.1600-0609.2007.00866.x 
20. Ferrari A, Bussaglia E, Ubeda J, Facchini L, Aventin A, Sierra J, Nomdedeu JF (2012) Immunophenotype distinction between acute promyelocytic leukaemia and CD15-CD34-HLA-DR- acute myeloid leukaemia with nucleophosmin mutations. Hematol Oncol 30(3):109-114. https://doi.org/10.1002/hon.1011

21. Kappelmayer J, Simon A, Katona E, Szanto A, Nagy L, Kiss A, Kiss C, Muszbek L (2005) Coagulation factor XIII-A. A flow cytometric intracellular marker in the classification of acute myeloid leukemias. Thromb Haemost 94(2):454-459. https://doi.org/10. 1160/TH05-03-0206

22. Simon A, Bagoly Z, Hevessy Z, Csathy L, Katona E, Vereb G, Ujfalusi A, Szerafin L, Muszbek L, Kappelmayer J (2012) Expression of coagulation factor XIII subunit A in acute promyelocytic leukemia. Cytometry B Clin Cytom 82(4):209216. https://doi.org/10.1002/cyto.b.21019

23. van den Ancker W, Westers TM, de Leeuw DC, van der Veeken YF, Loonen A, van Beckhoven E, Ossenkoppele GJ, van de Loosdrecht AA (2013) A threshold of $10 \%$ for myeloperoxidase by flow cytometry is valid to classify acute leukemia of ambiguous and myeloid origin. Cytometry B Clin Cytom 84(2):114-118. https://doi. org/10.1002/cyto.b.21072

24. Jafari K, Tierens A, Rajab A, Musani R, Schuh A, Porwit A (2018) Visualization of cell composition and maturation in the bone marrow using 10-color flow cytometry and radar plots. Cytometry B Clin Cytom 94(2):219-229. https://doi.org/10.1002/cyto.b.21519

25. Blanco E, Perez-Andres M, Arriba-Mendez S, ContrerasSanfeliciano T, Criado I, Pelak O, Serra-Caetano A, Romero A, Puig N, Remesal A, Torres Canizales J, Lopez-Granados E, Kalina T, Sousa AE, van Zelm M, van der Burg M, van Dongen JJM, Orfao A, PIDg EF (2018) Age-associated distribution of normal B-cell and plasma cell subsets in peripheral blood. J Allergy Clin Immunol. https://doi.org/10.1016/j.jaci.2018.02.017

26. Lacombe F, Campos L, Allou K, Arnoulet C, Delabarthe A, Dumezy F, Feuillard J, Genevieve F, Guerin E, Guy J, Jouault H, Lepelley P, Maynadie M, Solly F, Ballon OW, Preudhomme C, Baruchel A, Dombret H, Ifrah N, Bene MC, Groupe d'Etude Immunologique des L (2017) Prognostic value of multicenter flow cytometry harmonized assessment of minimal residual disease in acute myeloblastic leukemia. Hematol Oncol. https://doi.org/10. 1002/hon. 2488

27. Lhermitte L, Mejstrikova E, van der Sluijs-Gelling AJ, Grigore GE, Sedek L, Bras AE, Gaipa G, Sobral da Costa E, Novakova M, Sonneveld E, Buracchi C, de Sa Bacelar T, Te Marvelde JG, Trinquand A, Asnafi V, Szczepanski T, Matarraz S, Lopez A, Vidriales B, Bulsa J, Hrusak O, Kalina T, Lecrevisse Q, Martin Ayuso M, Bruggemann M, Verde J, Fernandez P, Burgos L, Paiva B, Pedreira CE, van Dongen JJM, Orfao A, van der Velden VHJ (2018) Automated database-guided expert-supervised orientation for immunophenotypic diagnosis and classification of acute leukemia. Leukemia 32(4):874-881. https://doi.org/10.1038/leu.2017. 313

28. van Dongen JJ, Lhermitte L, Bottcher S, Almeida J, van der Velden VH, Flores-Montero J, Rawstron A, Asnafi V, Lecrevisse Q, Lucio P, Mejstrikova E, Szczepanski T, Kalina T, de Tute R, Bruggemann M, Sedek L, Cullen M, Langerak AW, Mendonca A, Macintyre E, Martin-Ayuso M, Hrusak O, Vidriales MB, Orfao A, EuroFlow C (2012) EuroFlow antibody panels for standardized n-dimensional flow cytometric immunophenotyping of normal, reactive and malignant leukocytes. Leukemia 26(9):1908-1975. https://doi.org/ 10.1038/leu.2012.120

29. Ferrara F, Morabito F, Martino B, Specchia G, Liso V, Nobile F, Boccuni P, Di Noto R, Pane F, Annunziata M, Schiavone EM, De Simone M, Guglielmi C, Del Vecchio L, Lo Coco F (2000) CD56 expression is an indicator of poor clinical outcome in patients with acute promyelocytic leukemia treated with simultaneous all-transretinoic acid and chemotherapy. J Clin Oncol 18(6):1295-1300. https://doi.org/10.1200/JCO.2000.18.6.1295

30. Orfao A, Chillon MC, Bortoluci AM, Lopez-Berges MC, GarciaSanz R, Gonzalez M, Tabernero MD, Garcia-Marcos MA, Rasillo AI, Hernandez-Rivas J, San Miguel JF (1999) The flow cytometric pattern of CD34, CD15 and CD13 expression in acute myeloblastic leukemia is highly characteristic of the presence of PML-RARalpha gene rearrangements. Haematologica 84(5):405-412

31. Guglielmi C, Martelli MP, Diverio D, Fenu S, Vegna ML, CantuRajnoldi A, Biondi A, Cocito MG, Del Vecchio L, Tabilio A, Avvisati G, Basso G, Lo Coco F (1998) Immunophenotype of adult and childhood acute promyelocytic leukaemia: correlation with morphology, type of PML gene breakpoint and clinical outcome. A cooperative Italian study on 196 cases. Br J Haematol 102(4): 1035-1041

32. Matarraz S, Leoz P, Fernandez C, Colado E, Chillon MC, Vidriales MB, Gonzalez M, Rivera D, Osuna CS, Caballero-Velazquez T, Van Der Velden V, Jongen-Lavrencic M, Gutierrez O, Bermejo AY, Alonso LG, Garcia MB, De Ramon Sanchez C, GarciaDonas G, Mateo AG, Recio I, Sanchez-Real J, Mayado A, Gutierrez ML, Barcena P, Barrena S, Lopez A, Van Dongen J, Orfao A (2018) Basophil-lineage commitment in acute promyelocytic leukemia predicts for severe bleeding after starting therapy. Mod Pathol 31:1318-1331. https://doi.org/10.1038/ s41379-018-0038-2

33. Rahman K, Gupta R, Singh MK, Sarkar MK, Gupta A, Nityanand S (2018) The triple-negative (CD34-/HLA-DR-/CD11b-) profile rapidly and specifically identifies an acute promyelocytic leukemia. Int J Lab Hematol 40(2):144-151. https://doi.org/10.1111/ijlh. 12754

34. Paietta E, Andersen J, Gallagher R, Bennett J, Yunis J, Cassileth P, Rowe J, Wiernik PH (1994) The immunophenotype of acute promyelocytic leukemia (APL): an ECOG study. Leukemia 8(7): $1108-1112$

35. Kroschinsky FP, Schakel U, Fischer R, Mohr B, Oelschlaegel U, Repp R, Schaich M, Soucek S, Baretton G, Ehninger G, Thiede C, Group DS (2008) Cup-like acute myeloid leukemia: new disease or artificial phenomenon? Haematologica 93(2):283-286. https://doi. org/10.3324/haematol.11669

36. Park BG, Chi HS, Jang S, Park CJ, Kim DY, Lee JH, Lee JH, Lee KH (2013) Association of cup-like nuclei in blasts with FLT3 and NPM1 mutations in acute myeloid leukemia. Ann Hematol 92(4): 451-457. https://doi.org/10.1007/s00277-012-1645-5

37. Sainty D, Liso V, Cantu-Rajnoldi A, Head D, Mozziconacci MJ, Arnoulet C, Benattar L, Fenu S, Mancini M, Duchayne E, Mahon FX, Gutierrez N, Birg F, Biondi A, Grimwade D, LafagePochitaloff M, Hagemeijer A, Flandrin G, Groupe Francais d'Hematologie C, Groupe Francais de Cytogenetique H, Group UKCC, Malignancies BEC-CAMCDiH (2000) A new morphologic classification system for acute promyelocytic leukemia distinguishes cases with underlying PLZF/RARA gene rearrangements. Blood 96(4):1287-1296 